Pacific Journal of Mathematics

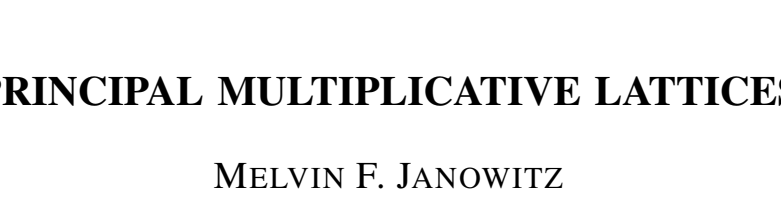




\title{
PRINCIPAL MULTIPLICATIVE LATTICES
}

\author{
M. F. JANOWITZ
}

P. J. McCarthy has recently proved that if $R$ is a Noetherian ring with unity, then every ideal of $R$ is a principal element of $L(R)$, the lattice of ideals of $R$, if and only if $R$ is a multiplication ring. It is shown here that an arbitrary commutative ring $R$ with unity is a Noetherian multiplication ring if and only if every ideal of $R$ is a principal element of $L(R)$.

1. M-lattices. The basic terminology and notation will follow that of [2] and [3]. It will be assumed throughout the paper that $L$ denotes a complete commutative and residuated multiplicative lattice. The results of this section, though well known, have apparently not been previously published. They are included here because they are needed to prove the results of $\S 2$.

THEOREM 1. The following conditions are equivalent:

(1) $L$ is an M-lattice.

(2) $(A: B) B=A \cap B$ for all $A, B \in L$.

(3) Every element of $L$ is meet principal.

Proof. $\quad(1) \Longrightarrow(2)$ Let $A, B \in L$. Since $A \cap B \leqq B$, we have $A \cap B=$ $B C$ for some $C \in L$. Then $B C \leqq A \Rightarrow C \leqq A: B$, so we have

$$
A \cap B=B C \leqq B(A: B) \leqq A \cap B .
$$

It follows that $(A: B) B=A \cap B$.

(2) $\Rightarrow(3)$ Given $A, B, M \in L$ we need only note that

$A M \cap B=(B: A M) A M=\{[(B: M): A] A\} M=[A \cap(B: M)] M$.

$(3) \Rightarrow(1)$ If $A M \cap B=[A \cap(B: M)] M$ for all $A, B \in L$ and if $B \leqq$ $M$ we have

$$
B=I M \cap B=[I \cap(B: M)] M=(B: M) M .
$$

Theorem 2. Every M-lattice is infinitely distributive.

Proof. Let $M=\cup_{\alpha} M_{\alpha}$ in the $M$-lattice $L$. Then for any $B \in L$, $B \cap M$ is an upper bound for $\left\{B \cap M_{\alpha}\right\}$. Let $X$ be any other upper bound for this set. Then for all $\alpha$,

$$
X: M_{\alpha} \geqq\left(B \cap M_{\alpha}\right): M_{\alpha}=B: M_{\alpha} .
$$

It is easily deduced that 


$$
X: M=\cap_{\alpha}\left(X: M_{\alpha}\right) \geqq \cap_{\alpha}\left(B: M_{\alpha}\right)=B: M .
$$

By Theorem 1 we have

$$
X \geqq(X: M) M \geqq(B: M) M=B \cap M .
$$

It follows that $B \cap M=\cup_{\alpha}\left(B \cap M_{\alpha}\right)$.

Theorem 3. Let $L$ be an $M$-lattice. Then $\left(\cup_{\alpha} A_{\alpha}\right): M=\cup_{\alpha}\left(A_{\alpha}: M\right)$ holds for all $A_{\alpha} \in L$ and for every principal element $M$ of $L$.

Proof. Let $A=\cup_{\alpha} A_{\alpha}$. By Theorem 2, $A \cap M=\cup_{\alpha}\left(A_{\alpha} \cap M\right)$. Hence $A: M=(A \cap M): M=\left[\cup_{\alpha}\left(A_{\alpha} \cap M\right)\right]: M=\left[\cup_{\alpha}\left(A_{\alpha}: M\right) M\right]: M=$ $\left\{\left[\cup_{\alpha}\left(A_{\alpha}: M\right)\right] M\right\}: M=\left[\cup_{\alpha}\left(A_{\alpha}: M\right)\right] \cup(0: M)=\cup_{\alpha}\left(A_{\alpha}: M\right)$.

2. Principal lattices. Though our goal is to investigate the lattice of ideals of a commutative ring with unity, it will cost us nothing to begin our discussion in the context of an $M$-lattice. In connection with this, it will prove convenient to call $L$ a principal lattice when each of its elements is principal.

Lemma 4. Let $L$ be an $M$-lattice whose unit element is compact. Every principal element of $L$ is then compact.

Proof. Let $M$ be a principal element of $L$ and assume that $M \leqq$ $\cup_{\alpha} B_{\alpha}$. Then by Theorem 3 ,

$$
I=\left(\cup_{\alpha} B_{\alpha}\right): M=\cup_{\alpha}\left(B_{\alpha}: M\right) .
$$

Since $I$ is compact there must exist finitely many indices $\alpha_{1}, \alpha_{2}, \cdots, \alpha_{k}$ such that $I=\bigcup_{i=1}^{k}\left(B_{\alpha_{i}}: M\right)=\left(\bigcup_{i=1}^{k} B_{\alpha_{i}}\right): M$. It follows that $M \leqq$ $\bigcup_{i=1}^{k} B_{\alpha_{i}}$ as desired.

Theorem 5. Let $L$ be an M-lattice whose unit element is compact. Suppose further that every element of $L$ is the join of a family of principal elements. An element $C$ of $L$ is then compact if and only if it is principal.

Proof. By Lemma 4 every principal element of $L$ is compact. On the other hand, if $C$ is compact then it is the join of a finite number of principal elements. It follows from the argument given in [3] that any such element is principal.

THeORem 6. Suppose that every element of $L$ is the join of a family of principal elements and that the unit element of $L$ is compact. The necessary and sufficient condition that $L$ be a principal 
lattice is that it be an M-lattice satisfying the ascending chain condition.

Proof. Assume first that $L$ is a principal lattice. By Theorem 1 it is an $M$-lattice, and by Lemma 4 each of its elements is compact. It follows that $L$ satisfies the ascending chain condition. For the converse, see [3], Theorem 1, p. 706.

COROLLARY. Let $L$ be an M-lattice satisfying the conditions of the theorem. Assume further that $0: A=0$ for all $A \neq 0$ in $L$. The ascending chain condition then holds in $L$.

Proof. Let $M \in L$ and write $M=\cup_{\alpha} M_{\alpha}$ with each $M_{\alpha}$ principal. It was shown in [3], p. 707 that for any $B \in L$,

$$
B M: M \leqq B \cup\left(0: M_{\alpha}\right)=B \text {. }
$$

It follows that $B=B M: M=B \cup(0: M)$ so that by [1], Theorem 1, p. $215, M$ is principal,

When viewed in the context of ring theory these results translate to the following:

THEOREM 5*. Let $R$ be a multiplication ring with unity. An ideal of $R$ is a principal element of $L(R)$ if and only if it is finitely generated. The necessary and sufficient condition that $L(R)$ be a principal lattice is that $R$ be Noetherian.

Theorem 6*. Let $R$ be a commutative ring with unity. The necessary and sufficient condition that $L(R)$ be a principal lattice is that $R$ be a Noetherian multiplication ring.

The corollary to Theorem 6 translates to the well known fact that an integral domain is a multiplication ring if and only if it is Dedekind.

In closing we mention a few easily established facts about the lattice of ideals of an arbitrary commutative ring with unity. First of all, an obvious modification of the proof of Lemma 4 will show that every principal element of $L(R)$ is finitely generated, thus answering a question posed by P. J. McCarthy ([4], p. 269). At this point it is easily shown that $L(R)$ satisfies Postulate $C$ of Ward (see [5], p. 631) if and only if $R$ is a multiplication ring with minimum condition, and that $L(R)$ is a Boolean algebra if and only if $R$ is a semiprime multiplication ring with minimum condition. 


\section{BIBLIOGRAPHY}

1. K. P. Bogart, Distributive local Noether lattices, Michigan Math. J. 16 (1969), 215223.

2. R. P. Dilworth, Abstract commutative ideal theory, Pacific J. Math. 12 (1962), 481498.

3. P. J. MeCarthy, Note on abstract commutative ideal theory, Amer. Math. Monthly 74 (1967), 706-707.

4. - Arithmetical rings and multiplicative lattices, Ann. Mat. Pura Appl. 82 267-274.

5. M. Ward, Residuation in structures over which a multiplication is defined, Duke Math. J. 3 (1937), 627-636.

Received August 18, 1969. Research supported by NSF Grant GP-11580. Presented to the Society January 5, 1970.

UNIVERSITY OF MASSACHUSETTS

Amherst, Massachusetts 


\section{PACIFIC JOURNAL OF MATHEMATICS}

\section{EDITORS}

\author{
H. SAMELSON \\ Stanford University \\ Stanford, California 94305 \\ Richard Pierce \\ University of Washington \\ Seattle, Washington 98105
}

J. DUGUNDJI

Department of Mathematics

University of Southern California

Los Angeles, California 90007

RICHARD ARENS

University of California

Los Angeles, California 90024

\section{ASSOCIATE EDITORS}
E. F. BECKENBACH
B. H. NEUMaNN
F. WOLE
K. YosHIDA

\section{SUPPORTING INSTITUTIONS}

\author{
UNIVERSITY OF BRITISH COLUMBIA \\ CALIFORNIA INSTITUTE OF TECHNOLOGY \\ UNIVERSITY OF CALIFORNIA \\ MONTANA STATE UNIVERSITY \\ UNIVERSITY OF NEVADA \\ NEW MEXICO STATE UNIVERSITY \\ OREGON STATE UNIVERSITY \\ UNIVERSITY OF OREGON \\ OSAKA UNIVERSITY \\ UNIVERSITY OF SOUTHERN CALIFORNIA
}

\author{
STANFORD UNIVERSITY \\ UNIVERSITY OF TOKYO \\ UNIVERSITY OF UTAH \\ WASHINGTON STATE UNIVERSITY \\ UNIVERSITY OF WASHINGTON

$* * *{ }^{*} *{ }^{*}$
AMERICAN MATHEMATICAL SOCIETY
CHEVRON RESEARCH CORPORATION
TRW SYSTEMS \\ NAVAL WEAPONS CENTER
}

The Supporting Institutions listed above contribute to the cost of publication of this Journal. but they are not owners or publishers and have no responsibility for its content or policies.

Mathematical papers intended for publication in the Pacific Journal of Mathematics should be in typed form or offset-reproduced, (not dittoed), double spaced with large margins. Underline Greek letters in red, German in green, and script in blue. The first paragraph or two must be capable of being used separately as a synopsis of the entire paper. The editorial "we" must not be used in the synopsis, and items of the bibliography should not be cited there unless absolutely necessary, in which case they must be identified by author and Journal, rather than by item number. Manuscripts, in duplicate if possible, may be sent to any one of the four editors. Please classify according to the scheme of Math. Rev. 36, 1539-1546. All other communications to the editors should be addressed to the managing editor, Richard Arens, University of California, Los Angeles, California, 90024.

50 reprints are provided free for each article; additional copies may be obtained at cost in multiples of 50 .

The Pacific Journal of Mathematics is published monthly. Effective with Volume 16 the price per volume (3 numbers) is $\$ 8.00$; single issues, $\$ 3.00$. Special price for current issues to individual faculty members of supporting institutions and to individual members of the American Mathematical Society: $\$ 4.00$ per volume; single issues $\$ 1.50$. Back numbers are available.

Subscriptions, orders for back numbers, and changes of address should be sent to Pacific Journal of Mathematics, 103 Highland Boulevard, Berkeley, California, 94708.

PUBLISHED BY PACIFIC JOURNAL OF MATHEMATICS, A NON-PROFIT CORPORATION

Printed at Kokusai Bunken Insatsusha (Internatıonal Academic Printing Co., Ltd.), 7-17, Fujimi 2-chome, Chiyoda-ku, Tokyo, Japan. 


\section{Pacific Journal of Mathematics}

\section{Vol. 33, No. 3 \\ May, 1970}

Charles A. Akemann, Approximate units and maximal abelian

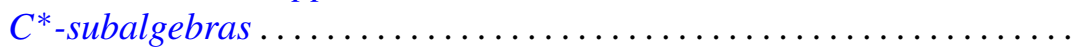

Gail Atneosen, Wild points of cellular arcs in 2-complexes in $E^{3}$ and cellular hulls

John Logan Bryant and De Witt Sumners, On embeddings of 1-dimensional

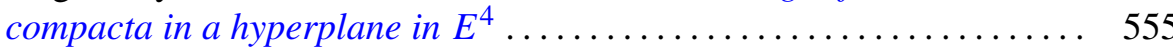

H. P. Dikshit, On a class of Nörlund means and Fourier series.......... 559

Nancy Dykes, Generalizations of realcompact spaces .............. 571

Hector O. Fattorini, Extension and behavior at infinity of solutions of certain linear operational differential equations .................. 583

Neal David Glassman, Cohomology of nonassociative algebras .......... 617

Neal Hart, Ulm's theorem for Abelian groups modulo bounded groups . . . . 635

Don Barker Hinton, Continuous spectra of second-order differential

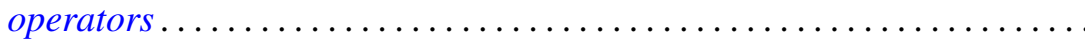

Donald Gordon James, On Witt's theorem for unimodular quadratic forms. II ............................................. 645

Melvin F. Janowitz, Principal multiplicative lattices................ 653

James Edgar Keesling, On the equivalence of normality and compactness in hyperspaces .................................... 657

Adalbert Kerber, Zu einer Arbeit von J. L. Berggren über ambivalente Gruppen

Keizō Kikuchi, Various $m$-representative domains in several complex variables

Jack W. Macki and James Stephen Muldowney, The asymptotic behaviour of solutions to linear systems of ordinary differential equations ....

Andy R. Magid, Locally Galois algebras . . . .

T. S. Ravisankar, On differentiably simple algebras......

Joseph Gail Stampfli, The norm of a derivation ..

Francis C.Y. Tang, On uniqueness of central decompositions of groups ...

749

Robert Charles Thompson, Some matrix factorization theorems. I .

763

Robert Charles Thompson, Some matrix factorization theorems. II . . 